\title{
The Role of Museum Education in Raising Undergraduate Pre-service Teachers' Disability Awareness: the Case of an Exhibition by Disabled Artists in Greece
}

\author{
Charikleia Kanari $^{1}$ \& Anastasia Zoi Souliotou ${ }^{1}$ \\ ${ }^{1}$ School of Humanities and Social Sciences, University of Thessaly, Greece \\ Correspondence: Charikleia Kanari, School of Humanities and Social Sciences, University of Thessaly, \\ Argonafton \& Filellinon, Volos, Greece. Tel: 0030-697-810-4310. E-mail: kanarixarikleia@ hotmail.com
}

Received: February 2, 2021

doi:10.5539/hes.v11n2p99
Accepted: March 11, $2021 \quad$ Online Published: March 21, 2021

URL: https://doi.org/10.5539/hes.v11n2p99

\begin{abstract}
In the frame of the worldwide policies towards inclusion there is a need of changes, systematic strategies and actions at different levels and settings of the society including education and cultural organizations. Museums, culture and arts have a constantly increasing role towards a more cohesive and inclusive society in terms of educational, social and cultural impact and for diverse social groups that face various barriers in their full participation in social life. Furthermore, museums as nonformal learning environments and art activities can complement different levels of formal education and courses towards a better understanding of diversity. The aforementioned are of particular importance for disabled people as well as for teachers who work with disabled children and for the enrichment of student teachers' training in issues of disability. The aim of the present study was to investigate issues of cultural representations and the reflections of undergraduate Primary Education teachers regarding disabled artists, arts, museum and education after a visit in a temporary art exhibition of disabled artists. The participants were 33 student teachers of a University Department in Greece who attended a Museum Education course and the data were obtained via questionnaires. The results revealed the value and the need for further learning opportunities in museums and other cultural environments as well as their potential contribution in combating stereotypes, enriching and broadening undergraduate Primary Education teachers' perceptions regarding disability with implications in the fields of Museum Studies and Museum Education, Arts, Higher Education, Special and Inclusive Education.
\end{abstract}

Keywords: Higher Education, Museum Education, informal and nonformal learning, student teachers, disabled artists, visual arts

\section{Introduction}

The development of an inclusive society that respects the diversity and promotes equal participation to all people across the spectrum of social life is a central topic of the international social agenda, policies, strategies and practices. In this framework the necessity of changes, collaborations and synergies at different levels and settings of society, as for example education and cultural institutions (e.g., museums), is underlined by many policy makers, organizations, researchers, etc. (see, e.g., Ainscow, 2020; Coxall, 2006; Kanari \& Souliotou, 2020; Spandagou, 2011; UNESCO, 2017). Undoubtedly education and learning as life time process and as a continuum in different contexts (Grajcevci \& Shala, 2016) is a very powerful factor towards inclusion and equity (Ainscow, 2020; UNESCO, 2015). In this line, museums' activities can also have a strong educational and social impact through a range of learning and social outcomes by supporting formal education, serving and representing different communities, promoting civic engagement, tackling discrimination and stereotypes and contributing to a better understanding and respect of diversity (Ambrose \& Paine, 2018; Black, 2012; Dodd \& Sandell, 2001; Hooper-Greenhill, Sandell, Moussouri \& O'Riain, 2000; Sandell, 2003). Furthermore, arts have certainly a crucial role for the sustainable community development, community engagement, social cohesion and the improvement of quality of life (Hawkes, 2001; Mowlah, Niblett, Blackburn, \& Harris, 2014). Both in the fields of museum studies and education the terms "inclusion", "inclusive museum" and "inclusive education" respectively are conceived with a broader view that embraces diversity among all people including disabled people (Ainscow, 2020; Black, 2012; Coxall, 2006). In the frame of the social model of disability, which places the emphasis on the societal barriers that exclude disabled people, a main issue - among other barriers - is the 
construction of cultural images and representations about disabled people. Relevant discussions and studies point out how cultural representations are at the same time "constitutive" and "reflective" of the way disability is conceived (Sandell \& Dodd, 2010:3) and stress the need for combating stereotypes and prejudices towards disability (Barnes, Mercer \& Shakespeare, 1999; Oliver, 1990). Thus, in the frame of the social model of disability and the dominant policy of inclusion and inclusive education, museums, arts, disability arts and the ways in which formal, informal and nonformal learning environments complement each other have benefits not only for disabled people and wider audience, but also for teachers who work with disabled children and for student teachers' education and training in issues of disability.

Museums are spaces of knowledge (see, e.g., Bennett, 1995) and "culturally authoritative institutions" (Dodd, Jones, Jolly \& Sandell, 2010:110), which, according to their current definition, serve the society through their functions (i.e., collecting, conserving, researching, displaying, and communicating the tangible and intangible cultural heritage and the human environment items) with the purpose of "education, study and enjoyment" (ICOM, 2017:3, see Note 1). In this framework Museum Education is a scientific field devoted to the educational role and mission of museums (Hein, 2006). Museums are learning environments that support structured formal education and groups engaged in formal education in many ways, as for example educational programs for schoolchildren, university students, etc. (Black, 2012; Hooper-Greenhill, 2007). They are also spaces of lifelong learning (Black, 2005; Gibbs, Sani- \& Thompson, 2007). Compared to structured formal standardized system of education (i.e., schools, universities), there is a lot of discussion about the context and the characteristics of learning in the museums which do not require specific qualifications, assessment according to external standards, etc. (Hein, 1998; Hooper-Greenhill, 2006, 2007; Kanari \& Souliotou, 2020). Based on criteria related to a. the organizational and administrative differences between formal structured education and other learning environments, as for example museums (Hein, 1998), b. the characteristics of learning in the museums which are more flexible, open, experiential and audience-centered, (Black, 2005, 2012; Hein, 1998; Hooper-Greenhill, 2007), and c. the type of the activities and the target audiences within museums (Black, 2012; Hein, 1998; Hooper-Greenhill, 2007; McGhie, 2020), researchers of the museums' field adopt the terms "informal" and "nonformal" learning alternatively to describe different type of activities and characteristics of learning in the museum (see, e.g., Hein, 1998; Hooper-Greenhill, 2007; McGhie, 2020; Nikonanou, Bounia, Bennett \& Kirwan, 2020). Thus, museums are considered as "informal" and "free-choice learning" environments related - among other - to leisure activities (Falk, Dierking \& Adams, 2006; Falk \& Dierking, 2013) and many museum educational activities fall under the umbrella of "informal" learning (McGhie, 2020). Museum learning can also describe "informal and adult learning strategies" (Nikonanou et al., 2020:5). The term "nonformal" is used within museums for planned activities out of formal educational settings (e.g., educational programs and visits of schools at museums), training events and courses for different target audiences, etc. (Eshach, 2007; Kanari \& Souliotou, 2020; McGhie, 2020; Nikonanou et al., 2020; Vartiainen \& Enkenberg, 2013).

The present study aims to investigate how museum learning environment and art exhibitions of disabled artists encourage undergraduate teachers to reflect on their own perceptions regarding disability and disabled artists. It is argued that Museum Education in terms of educational and social responsibility (Hein, 2006), arts and museums' activities related to disability, should enrich the dialogue, practices and experience regarding teachers' pre-service or/and in-service training and education towards disability both in formal and nonformal learning environments, courses, programs and activities.

\section{Theoretical Framework}

\subsection{Museums, Social Inclusion, Arts and Disability Awareness}

The discussion about the educational and social role of museums is constantly expanding taking into account the vast changes and challenges that arise and are visible in all sectors of social life (Black, 2012.Hansen, 2014) including issues of human rights, diversity and the existing social inequalities (McGhie, 2020). Alongside with the discussion about the educational role of museums and a range of expected learning outcomes -knowledge, skills, values, creativity, progress, etc. (Hooper-Greenhill, 2007) - many researchers have studied the social role of museums and the impact of museum activities and practices towards social inclusion (see, e.g., Dodd \& Sandell, 2001; Hooper-Greenhill et al., 2000; McGhie, 2020; Newman, McLean \& Urquhart, 2005; Sandell, 2003). According to Dodd and Sandell (2001), the social impact of museum is beyond accessibility provisions and other outreach programs, although these practices are critical conditions and parameters for persons who face different types of barriers in their access to cultural goods and museums and they are excluded for different reasons (Weisen, 2008). The authors (Dodd \& Sandell, 2001), based on a conceptual framework that combines both the process and the social impact of museum work, revealed three levels of impact - individual, community and societal level - and a range of outcomes that enhance social inclusion. Although museum practices and 
activities have overlapped goals among the aforementioned levels about social inclusion, focusing at societal level, the social impact concerns the broader society. It refers to outcomes and values with regards to the combating of stereotypes, discrimination and racism, understanding, respect and positive attitudes towards diversity, identities, etc. This can be achieved through a range of practices and activities in terms of collective policies, displaying, interpretation, programs, etc. The aforementioned are of particular importance for various social groups including disabled people. Museums, based on their resources and through their collections, programs, exhibitions, interpretative means and other initiatives, can contribute to the enhancement of social inclusion of disabled people.

In the frame of the social model of disability the cultural images and representations about disability through arts, cinema, media, advertising, literature, etc., have been a topic of criticism since the dominant images of disabled people often reinforce stereotypes and prejudices: for example, as weak persons, victims, superheroes, etc. (Oliver, 1990). In the case of museums, one of their main characteristics is their "power" to create narratives and construct cultural representations (Dodd \& Sandell, 2001; Sandell, 2003; Sandell \& Dodd, 2010). Based on this assumption, the issue of "hidden histories", the degree and the way of presence or absence of the history of different people and social groups - including disabled people - is an important topic of discussion within museums in terms of inclusion and equality (see, e.g., Allday, 2009; Delin, 2002; Dodd, Sandell, Jolly \& Jones, 2008; Martins, Semedo, \& Camacho, 2018; Sandell et al., 2010). The social model of disability has been the basic theoretical framework within museums not only about accessibility but also about the ways that disabled people are portrayed, presented, under-presented or mis-presented within museums' collections even if the latter happens unintentionally (see, e.g., Sandell \& Dodd, 2010; Sandell, Delin, Dodd \& Gay, 2005). Similarly, in the frame of the social model of disability, arts are not considered as a therapeutic tool but as a cultural process and product (Oliver, 1990) placing the emphasis on social, political and cultural aspects and challenging ableist discourse and ideologies (Eisenhauer, 2007). Many museums around the world organize exhibitions with disabled artists' work or with themes related to disability. The international scene has many examples of relevant initiatives, projects and practices within museums (see, e.g., Cachia, 2013, 2014; Jacobson \& McMurchy, 2010; Martins et al., 2018; McCulloh, 2013; Sandell et al., 2010). Despite the existing differences among museums and countries due to various reasons (e.g., cultural context, funding, associations of disabled people or disabled artists, availability of museum resources, etc.), the aforementioned issues are topics of intensive, ongoing and intersectional discussions.

Thus, relevant research and museum initiatives (see e.g., Sandell, Dodd \& Garland-Thomson, 2010), reveal the ways in which these practices reinforce stereotypes or instead promote respect and better understanding of disability. Furthermore, they also show the complexity of this subject and the challenges in terms of museums' methods, collective and curatorial practices, considerations and approaches, art exhibitions with activist or without political intent, collaborative practices, participation of activist disabled artists or disabled artists who may not want to associate their art with their disability, activities, programs and practices and of course visitors' responses to these initiatives (Cachia, 2013; Delin, 2002; Dodd, Jones, Jolly \& Sandell, 2010; Martins et al., 2018; Sandell, 2007; Sandell \& Dodd, 2010). The latter, i.e., visitors' responses, is another critical parameter based on the constructivist learning theory that has influenced museums recognizing the active role of people and visitors in the learning process and how they construct meanings individually and socially, based -among other- on their prior knowledge, perceptions, experiences, etc. (Hein, 1991, 1999). Similarly, the conceptual model of learning and experience in museum alongside the physical and sociocultural context, place emphasis on the personal context which refers -among other- to prior knowledge, experiences, motivation, expectations, etc., which affect the museum experience even before the visit to the museum (Falk \& Dierking, 2000, 2013). In this framework museum professionals take into account that learning in the museum does not only include the messages of a museum exhibition, but also "what meaning the visitor chooses to make of the museum experience" (Falk, Dierking \& Adams, 2006:325). In the case of museum practices and activities related to disability, research findings about disabled and non-disabled visitors' responses in relevant projects, programs and exhibitions, revealed a range of responses that were influenced -among other- by personal experiences, beliefs and perceptions (Dodd et al., 2010). The aforementioned issues are of great importance for the broader society as well as for specific target audiences, as for example in-service teachers and undergraduate pre-service teachers who will be potentially working with disabled children.

\subsection{Inclusive Education, Teacher's Role and Disability Awareness}

In the frame of the worldwide predominant policy of inclusive education (UNESCO, 1994), much of the relevant literature and research over the past decades has stressed the interest on teachers' role among other critical parameters for the systematic modifications at different levels in schools and society (Ainscow, Dyson \& Weiner, 
2013; UNESCO, 2017). Indeed, teachers' role is considered as a key element not only for the effective teaching and collaborative practices, but also for the schools' improvement and the fostering of inclusive education in general (Ainscow, 2020; Ainscow et al., 2013; Hsiao, 2020; Sharma, Forlin \& Loreman, 2008). In the case of disabled children and/or children with special educational needs with regards to "inclusive education" it is generally accepted that courses in disability education are extremely important in order to increase student teachers' knowledge, skills, competencies and positive attitudes towards disability and inclusive education (see, e.g., Avramidis \& Norwich, 2002; Harvey, Yssel, Bauserman \& Merbler, 2010; Hsiao, 2020; Sharma et al., 2008). Furthermore, based on the assumption that attitudes towards disability affect teachers' expectations and practices, other researchers stressed their interest in the investigation of teachers' attitudes towards inclusive education as well as "disability per se" (Campbell, Gilmore \& Cuskelly, 2003:370).

In this "framework" many researchers all over the world investigate aspects of teachers' education in disability with regards to: the effectiveness of structured information-based courses in disability education, not only in terms of knowledge, but also in relation to changes of attitudes towards a more positive direction (Campbell et al., 2003; Tait \& Purdie, 2000); content infusion approach or separate and stand-alone courses and units (Sharma et al., 2008); collaborative practices between general and special educators even at the stage of pre-service teachers' training and education (Voltz \& Elliot, 1997 as cited in Harvey et al., 2010) and opportunities for authentic experiences (Jobling \& Moni, 2004); courses content in relation to teaching strategies, as for example differentiated instruction, pedagogical approaches, methods, practices and techniques, practicum in inclusive settings, competencies and skills, self-efficacy, etc. (Li \& Cheung, 2019; Sharma et al., 2008; Sokal, Woloshyn \& Funk-Unrau, 2013); experiences and contact with disabled people in the context of carefully designed activities and programs (Avramidis \& Norwich, 2002; Hsiao, 2020); fieldwork activities and experiential activities (Campbell et al., 2003); the role of the arts and disability arts in student teachers' education (Allan, 2014; Symeonidou, 2020; Ware 2008); considerations and need for further research regarding the long-term impact of various relevant practices and issues related to different cultural contexts (Loreman, Sharma \& Folin, 2013; Sharma et al., 2008), etc. The above aspects of teachers' training and education in disability and inclusive education reveal the complexity and the significance of various, complex and interrelated factors that influence their perceptions, attitudes and practices towards inclusive education and disability (Ainscow et al., 2013; Avramidis \& Norwich, 2002; Avramidis \& Kalyva, 2007; Zoniou-Sideri \& Vlachou, 2006).

Thus, in order to promote more positive attitudes towards disability and inclusive education in pre-service teachers, it is important to enrich and foster undergraduate teachers' training formal courses with other experiential activities, learning opportunities and experiences with disabled people (Campbell et al., 2003). In this framework it is argued that it is important to consider the role of dominant cultural representations and images about disability (Oliver, 1990) and how culture, arts, disabled artists' role and work as well as activities in nonformal learning and stimulating cultural environments, as for example museums (Black, 2012), affect perceptions towards disability or how they can encourage student teachers to reflect on their own perceptions and conceptions through an alternative and creative path.

\section{The Study Framework}

\subsection{Arts, Disability and Disabled Artists in the Greek Context}

The cultural, sociopolitical and economic context of each country turns out to be crucial when it comes to the support and promotion of the art of disabled people. The case of Greece indicates the role of educational, legislative and accessibility policies (Koltsida \& Lenakakis, 2017) as well as the significance of support and funding in order to substantially adopt the social model of disability and offer access and participation to the arts for all people (British Council - Disability Arts International, 2019). Some basic initial steps are detected during the 80s and 90s with the foundation of the Greek Deaf Theater and the "ARTOGETHER, Art by People With and Without Disabilities" (former "Very Special Arts") respectively (British Council - Disability Arts International, 2019; Koltsida \& Lenakakis, 2017). Despite the existing obstacles at different levels, it is worth mentioning that the art scene of and for disabled people during the last years has a remarkable evolution due to efforts, initiatives, programs, movements of disabled artists and funding within the context of various European projects, cultural and nonprofit organizations. The fruit of these endeavors is the current art scene of disabled people in Greece which counts various forms of bodies and mixed art groups as well as independent disabled artists (British Council - Disability Arts International, 2019).

More analytically, in Greece there are examples of: artistic events (theater and dance performances, concerts, performances, exhibitions, screenings) and festivals organized by disabled artists, mixed art groups and disabled artists' movements in terms of Universal Design (British Council - Disability Arts International, 2019); festivals 
for disability in art (Note 2); art exhibitions in cultural organizations about disability by non-disabled artists inspired for example by blindness (Kalaitzaki, 2018) or by Sign Language (Lazarou, 2020) accompanied by other events (e.g. touch tours for blind visitors and guided tours in Greek Sign Language or events, as for example recitation of poems with interpretation in Greek Sign Language respectively) and with the support of the associations of disabled and Deaf people (i.e., the Lighthouse for the Blind of Greece and the Hellenic Federation of the Deaf); art exhibitions about disabled famous artists, as for example the exhibition about Goya and Beethoven in Teloglion Foundation in Thessaloniki (2011) which brought together these two masters of visual arts and music respectively, under their common loss of hearing in their lives (Note 3); Association of Mouth and Foot Painting Artists in Greece (ZOSP, Note 4), as member of the VDMFK - Association of Mouth and Foot Painting) who also organized an international exhibition at the Zappeion in Athens (2014) with the participation of mouth and foot painting artists from different countries around the world (Note 5); art exhibitions and events by disabled visual artists, as for example the case of Petros Roukoutakis (1953-2015), a famous Greek blind visual artist; art exhibitions in museums by Deaf artists, as for example the exhibition entitled "Identities" at the Archaeological Museum of Patras (Koutsoubelitsi, Chavela, \& Manolopoulou, 2020), mixed art group exhibitions, as for example in the case of the group "En Dynamei" (British Council - Disability Arts International, 2019) and group exhibitions like the one of the present paper (ARTOGETHER, 2019). Although the current situation indicates a direction towards inclusion and a more intense interest about arts and disability, there is still room for further and more systematic promotion of relevant events in terms of accessibility as well as promotion of artistic events by disabled artists (British Council - Disability Arts International, 2019). Furthermore, it seems that there is a lack of research or published studies about audiences' responses regarding museums' relevant exhibitions.

\section{2 "Travelling Art": The Case of an Art Exhibition of Disabled Artists}

The present study was conducted in the frame of an art exhibition of disabled artists in a local museum in Greece. More precisely, the art exhibition entitled "Travelling Art" was an initiative by the non-profit organization "ARTOGETHER- Art by People With and Without Disabilities". The exhibition was the result of a two-year program with the aim to bring together disabled and non-disabled artists -more specifically disabled visual artists and non-disabled writers- in the frame of inclusive practices (Note 6). In the case of disabled visual artists, it is worth mentioning that a first basic step was the search on volunteer basis of disabled visual artists in order to reassure the equal opportunity of participation in this initiative. A five-member committee has selected, by a number of participants, the works of twenty-five disabled visual artists for the exhibition. It is important to note that the members of the selection committee did not know the artists' type of impairment, in order to focus mainly on the artworks themselves. Furthermore, twenty-five writers were invited to participate in the exhibition providing manuscripts inspired by the artworks without having any information about the type of impairment of the artists. Thus, the exhibition included different artworks alongside with the writers' manuscripts (ARTOGETHER, 2019). The exhibition ran first in Athens (October 2019) and then travelled in different museums of the museum network of the Piraeus Bank Group Cultural Foundation (PIOP) which are located in different cities of the Greek province (Note 7). However, this "travel" was interrupted due to pandemic COVID-19 and the exhibition ran only in two museums of the PIOP museum network.

The artists used a wide range of painting, sculpture and photography techniques embracing various subjects. More analytically, their painting materials include oil colors, acrylics, watercolors, ink, markers, mixed media and digital painting on various supports: canvas, cardboard, wood and paper. The sculptures were also made of variable materials including wood, glass, wire and cloth. There were also artworks which are inscribed in the collage and assemblage tradition, readymade artworks (e.g., object with cloth and wire which has been transformed into a mixed media artwork), crafts with decoupage and crackle techniques on a glass bottle and photographs. The subject of the artworks did not necessarily relate or directly reflect the artists' disabilities and experiences. Many of the artworks reflected artists' personal sight about nature, urban environment, still life, matter, geometric compositions and other decorative patterns, human figures, entertainment and festive moments. There were also artworks with indirect messages and hints of the artists' experiences in relation to human life or disability and other artworks with direct and clear reference to disability. In addition, some Deaf artists referred through their works to the Deaf culture and Sign Language or reflected the experience of a world without sound and issues of communication (ARTOGETHER, 2019). In line with the concept of this initiative, the labels of the exhibition in the museums did not provide any information about the type of impairment of the artists. Some information about disabled artists and their works were provided in the exhibition catalogue or in the context of guided tours. Thus, without some type of mediation, direct or not direct (e.g., a guided tour, catalogue, internet information, etc.), a visitor did not have information about the specific type of impairment or biography of each 
visual artist through museum labels.

\subsection{Research Questions}

The present study refers to a specific case of a planned visit of Primary Education student teachers (STs) to an art exhibition by disabled artists in a museum. The main aim was to investigate how their prior knowledge and experience of disability and disabled artists affect their expectations about an art exhibition of disabled artists before the visit to the museum as well as their views and reflections after the visit to the museum about disabled artists and the role of museums towards understanding of disability through relevant practices (i.e. art exhibitions with disabled artists and relevant programs). More precisely, the research questions were the following:

1. What were the student teachers' prior knowledge and experience in relation to disability and disabled artists?

2. What were their expectations about the art exhibition of disabled artists before the visit to the museum?

3. What were the student teachers' reflections after seeing the exhibition?

4. What were the student teachers' views about the educational and social value of relevant practices within museums for children, teachers and broader society?

\subsection{Significance of the Study}

The significance of the present study draws on a synthesis of critical educational and social issues which shape a cross-disciplinary, intersectional and more holistic approach. More precisely, it connects museums' role, cultural representations and images about disabled people, disability arts, inclusion, student teachers' training in issues of disability, constructivism learning theory and contemporary trends regarding synergies and educational activities in formal and nonformal learning environments. Thus, the results of the present study should lead to further research and practices with potential implications in different scientific, educational and cultural fields including Museum Education, Higher Education, arts, disability arts, culture, special and inclusive education. Furthermore, the case of the present study refers to practices within museums for student teachers' awareness in disability issues. It is considered of critical importance to include and enrich student teachers' training courses with activities related to arts, disabled artists in nonformal learning environments, as for example in museums, taking advantage of their relevant practices and resources with regards to disability. It can also be associated with other relevant studies that underline the role of arts, disability arts and disabled artists' work in the education of student teachers and the promotion of inclusive education and society (Allan, 2014; Symeonidou, 2020; Ware, 2008). In this framework, the present study is expected to enrich the existing relevant discussions about stereotypes, disability arts and inclusion providing an alternative way of student teachers' learning and training in disability issues in museums. The present study is also significant for museums in terms of visitors' responses in relevant practices and activities related to diversity and disability at a broader audience (Dodd et al., 2010), or/and specific target groups as for example teachers.

\section{Method}

\subsection{Instrument and Research Design}

As mentioned above, the present study refers to a specific case of an art exhibition of disabled artists and a specific visit to this exhibition with undergraduate pre-service teachers who attended a Museum Education course. The data were obtained via questionnaires and the completion was optional and anonymous. The use of questionnaires was felt more appropriate in order to reassure that the undergraduate students feel free and safe to express themselves knowing that their responses would not influence in any way their performance in the Museum Education course. Furthermore, the questionnaire included mainly open-ended questions (Qs) so as students describe in their own words issues regarding their opinions, prior knowledge about disabled artists, reflections, etc. The participants were informed and aware of the aims of the study and issues of permission and anonymity - as mentioned above - were reassured. The questionnaire was developed by the authors based on the relevant literature regarding the development of questionnaires (e.g., issues of clarity, comprehension, etc.) and according to the research aims of the present study (Cohen \& Manion, 1994; Creswell, 2015). More analytically the questionnaire consisted in total of 11 questions (open-ended and closed-ended questions) and it was structured in four axes regarding STs': a. demographic characteristics, b. prior knowledge and experience regarding disability and disabled artists, c. expectations and views regarding their experience of the specific art exhibition, and d. opinions regarding the educational and social value of museum art exhibitions and activities related to disability and disabled artists. The last axe was investigated with the use of Likert-type scale so that participants could rate their answers for specific questions/statements from 1 (minimum value) to 5 (maximum value) (Creswell, 2015). 
Regarding the procedure of data collection, it is important to note that before the visit to the museum there were no pre-visit activities or discussions about disability and disabled artists. This was a deliberate choice in order to allow STs to explore disabled artists' works without being influenced by issues, as for example the type of impairment of the artists. In the museum, STs did not attend a "traditional" tour but instead they followed an educational tour (Nikonanou et al., 2020) designed specifically for the STs' visit. The whole planning of the educational tour aimed to the active engagement and involvement of STs and not to convey and provide simply information (Black, 2012). During the educational tour, STs first had the time to see the exhibition on their own and were encouraged to discuss and share their first impressions and ideas. Then, the emphasis was placed upon the visual analysis of a number of selected artworks. Based on discursive methods and experiential activities (Black, 2012; Nikonanou et al., 2020), STs were encouraged to observe specific artworks, participate and discuss via open-ended questions, communicate ideas, express their views and personal interpretations. After the visual analysis, information was given about the type of the impairment of the artists or meanings related to disability experience in the case of specific artworks. STs filled in the questionnaire right after the visit to the art exhibition of disabled artists in the museum.

The analysis of the quantitative data derived from closed-ended questions was held with the SPSS -Statistics 23.0 Software and with content analysis for the qualitative data derived from the open-ended questions (Dey, 1993). A code system was adopted for the data analysis (ST1, ST2, etc, meaning Student Teacher 1, Student Teacher 2, and so on) and the authors of the present study collaborated for the analysis of the qualitative data (open-ended questions) (Robson, 1997).

\subsection{Participants}

The participants in the present study were 33 Primary Education student teachers (STs) who were attending a higher education course in Museum Education in Greece and they participated in an educational tour in the context of the art exhibition "Travelling Art". The majority of the participants were at the 2 nd semester of their studies $(54.55 \%, \mathrm{~N}=18 / 33)$. Nine of them were at the 4 th semester $(27.27 \%, \mathrm{~N}=9 / 33)$ and six of them were at their 8th semester of their studies $(18.18 \%, \mathrm{~N}=6 / 33)$. Their age ranged from 18 to 24 years and the majority of them were females.

\section{Results}

The $1^{\text {st }}$ research question (see Section 3.3.) about STs' knowledge and experience in relation to disability and disabled artists was considered important in order to see how it affects their expectations and learning process, based on the constructivist learning theory (Hein, 1991, 1999) and the conceptual model of learning and experience in museum (Falk \& Dierking, 2000, 2013), as described in Section 2.1. Thus, the first three questions (Qs) of the questionnaire, investigated STs' previous knowledge generally about disability, experiences or relationship (if any) with disabled people, previous knowledge specifically about disabled artists and any prior experience of relevant museum exhibitions respectively.

Based on the STs' answers in the first question (Q1: "Do you have any background knowledge or experience regarding disability or/and disabled persons? [Yes or No]"), more than half of the participants (54.55\%, $\mathrm{N}=18 / 33$ ) did not have any kind of relevant knowledge or experience in disability issues. It is important to note that in this question (Q1), STs who had some knowledge or experience about disability could choose more than one answer with regards to: a. university courses in Special Education, b. seminars in Special Education, c. relationship with disabled people (family, friends, etc.), and d. other. All STs of the $8^{\text {th }}$ semester reported that they had attended courses for Special Education in the University and therefore had some knowledge regarding the education of children with disabilities. Regarding other experiences in relation to Special Education, disability in general or disabled people, STs also reported having attended seminars in Special Education (9.09\%), relationship with disabled people (12.12\%) as for example university colleagues, or other experiences (12.12\%) during school years, as for example classmates with disabilities and disability awareness activities in school (e.g., activities during Christmas between general and special schools or other school projects).

Regarding STs' knowledge specifically for disabled artists (Q2: "Before the visit in the specific art exhibition have you ever heard about disabled visual artists or disabled artists? [Yes or No]. If yes, please explain below"), it was revealed that the STs had a limited or no prior knowledge about disabled artists. More analytically, based on the quantitative data of the Q2, the majority of STs $(63.64 \%, \mathrm{~N}=21 / 33)$ reported that they had heard about disabled artists before the visit to the art exhibition. However, based on the given examples in the specific open-ended question (Q2: "If yes, please explain below") by the STs who answered that they had heard about disabled artists, their knowledge refers to the following categories: a. mouth and foot painting artists, $b$. disabled singers, c. Deaf theater, and d. other. More precisely, more than half of them mainly knew mouth and foot 
painting artists. STs' knowledge about mouth and foot painting artists derives mainly from cards or calendars with relevant artworks that usually are sent from associations of disabled persons in Christmas period or even from random experiences:

"I know about artists who paint with their mouth or foot" (ST22). "Every Christmas my family buys cards for Christmas wishes that are from disabled artists" (ST1). "My mother has been subscribed in an association of painters with disabilities who send cards and calendars every Christmas with their artworks and paintings with mouth" (ST4). "Yes, I have heard about painters who paint with their mouth or foot and I have seen their artworks in cards" (ST18). "I have seen persons without hands painting out in the streets with their mouth who also have some other skills" (ST28).

Two STs reported that they had heard about disabled singers and Deaf theater respectively, without providing more specific examples. In other cases, STs answered with more general comments, without specific examples or with references to information heard on TV:

"I know about singers with disabilities and painters" (ST3). "I have heard about people who paint with their mouth and also theater with Deaf actors" (ST32). "I have heard about disabled persons who are engaged in art" (ST10). "I have heard about disabled visual artists but I don't know their names" (ST21). "I have also watched some TV programs about persons with disabilities" (ST17).

None of the participants, who declared in Q1 that they had attended university courses or seminars for Special Education, reported any knowledge about disabled artists derived from these courses or seminars.

Furthermore, in relation to STs' experience about disabled artists, based on the answers in the third question (Q3: "Before visiting this art exhibition, have you ever seen other art exhibitions with disabled artists? [Yes or No]. If yes, please explain below"), the vast majority of the participants $(96.97 \%, \mathrm{~N}=32 / 33)$ had never seen before a similar art exhibition. Even in the case of the ST who answered that had some similar experience, this was again about calendars with selected paintings by disabled artists and not art exhibitions of disabled persons.

Regarding the $2^{\text {nd }}$ research question and STs' expectations about the art exhibition of disabled artists ("Travelling Art") before the visit in the museum, based on the analysis of the qualitative data derived from the relevant open-ended question $(\mathrm{Q} 4:$ "Before the visit to the specific art exhibition what did you expect to see in relation to the artworks of disabled artists? "), STs' expectations included a. issues in relation to the content, i.e. subject, of the artworks, b. specific types of artworks in terms of techniques, materials and media, and c. issues in relation to the exhibition design and context (Table 1):

Table 1. Student teachers' expectations from the art exhibition of disabled artists

\begin{tabular}{ll}
\hline Categories & Subcategories \\
\hline Artworks content/subject & Direct representation of artists' disability \\
& Difficulties of disabled people in daily life \\
& Pain due to disability \\
& Emotions of disabled people \\
& Feelings about disability \\
& Feelings about life without disability \\
& Artworks with disabled people \\
& Other general topics or themes \\
& Paintings \\
& Mouth and foot paintings \\
& Artworks of clay \\
& "Asymmetrical", "bizarre" artworks made in "different" \\
& ways and with "different" materials \\
& Photography \\
& Poetry of disabled people \\
Mypes of artworks & Museum labels with information about artists' disability \\
& \\
\hline
\end{tabular}

As seen in the above Table (Table 1), regarding the artworks' content/subject, the STs' expectations were mostly in relation to the representation of disability. STs expected to see how disabled artists express their disability, how they present their "difficulties", their "problem" or their "pain", how they imagine their life without disability and generally "strong emotions". Only few STs responded that they did not expect something 
particular with regards to the content of the artworks. However, even in this case it seems that they were expecting to see or to understand the type of the artists' impairment or experiences of disability. Furthermore, a ST reported that he/she was expecting to see photographs with disabled people. Some indicative extracts are the following:

"[I was expecting to see] mainly artworks that would reflect the disability of each artist" (ST21). "Drawings with strong emotions and direct representation of the artists' disabilities" (ST16). "I was expecting to see that artists with disabilities would express their difficulties in daily life through their artworks" (ST10). "Artworks that would express the pain of persons with disabilities" (ST19). "[artworks] with references to their problem" (ST17). "I was expecting to see artworks in relation to their disability or/and how they imagine their life without disability" (ST7). "I was not expecting something different but perhaps the type of their disability" (ST11). "I was expecting to see different topics that express them or inspire them or to talk about their daily life through their paintings" (ST27). "[Artworks] full of intensive emotions" (ST23). "I was expecting to see photographs with persons with disabilities" (ST25).

Regarding STs' expectations in relation to specific types of artworks in terms of techniques and materials, STs reported that they expected to see mainly paintings, mouth and foot paintings and artworks of clay, strange artworks, made in "different ways" or with "different materials". In the latter case, STs did not provide further explanations. Some representative extracts are presented below:

"I was expecting to see mainly paintings, not sculptures" (ST22). "I was thinking that the exhibition was about mouth or foot paintings" (ST8). "I was expecting to see paintings mainly "asymmetrical", artworks of clay or other materials" (ST2). "... artworks with bizarre pictures but with strong messages" (ST27). "Paintings, other artworks, poetry of persons with disabilities..." (ST17). "I was expecting to see paintings made in different ways and full of intensive emotions" (ST23).

The last category of the STs' responses that was revealed, with regards to their expectations before the visit to the art exhibition of disabled artists in the museum, refers to the exhibition design and context. More specifically, STs were expecting to have information about each artist's impairment in the labels of the exhibits or to learn stories of disabled people:

"I was expecting to see in the labels the type of disability of the artists" (ST4). "I was expecting to see the artists to reveal their skills or their stories" (ST28).

The 3rd research question of the study refers to STs' reflections on their experience from their visit in the museum and the exhibition "Travelling Art". Based on the qualitative data derived by the relevant open-ended question (Q5: "After the visit to the specific art exhibition could you describe your thoughts, ideas, feelings, etc., and in relation to your prior expectations?"), STs' answers fall under the following categories: a. knowledge regarding disabled artists' diverse interests and ways of art expression, b. capabilities of disabled artists and disabled people in general, c. ideas about appropriate behavior towards disabled people, d. design and context of the exhibition, and e. process of the educational tour (Table 2):

Table 2. Student teachers' reflections after visiting the art exhibition of disabled artists

\begin{tabular}{ll}
\hline Categories & Subcategories \\
\hline Knowledge regarding disabled & Artworks with disability themes \\
artists' diverse interests and & Artworks with a range of content/subject \\
ways of art expression & Deaf culture \\
& Use of various means and media \\
Capabilities of disabled artists & Equality between disabled and non-disabled artists \\
& Overestimation of the disabled artists' and people's \\
& talent and skills \\
Appropriate behavior towards disabled people & Avoiding discrimination \\
& Avoiding pity, underestimation \\
& Respect diversity \\
& Opportunities to disabled people \\
Design and context of the exhibition & Information on museum labels \\
& Multiple messages \\
Process of the educational tour & Observation \\
& Discussion \\
& Expression \\
& Discover meanings \\
\hline
\end{tabular}


More analytically, STs commented on the range of artworks' types in terms of media, means, content and subject of the artworks and the language of Deaf artists (i.e., Sign Language). The following extracts include STs' both prior expectations and their reflections after the visit to the museum:

"I was expecting to see that artists with disabilities would express their difficulties in daily life through their artworks. There were some artworks with clear pictures of disability but many of them were not about this. Unless I knew that it was an exhibition of artists with disabilities, I would not be able to see any differences, for example looking at paintings or other artworks of non-disabled artists" (ST10).

"I was expecting to see mouth and foot paintings or clay artworks or something. It was a new experience with so many different artworks..." (ST6).

"Artworks about disability, difficulties, etc. I was impressed by the artworks of Deaf artists when seeing their language" (ST20).

"I was thinking that the exhibition was about mouth or foot paintings. I saw different artworks, sculpture, materials like glass ...different themes, not always about disability, flowers, landscapes, etc.” (ST8).

"Artworks that would express the pain of persons with disabilities. I realized that people with disabilities have various interests and ways of seeing the world" (ST19).

STs also expressed their thoughts about "capabilities of disabled artists and disabled people in general" on an equal basis with non-disabled people. However, two STs expressed some ideas with an overestimation of the potential of disabled people or disabled artists compared to the non-disabled. The following extracts are representative of the aforementioned ideas:

"I was expecting that the way disabled artists express themselves would be more intense and apparent. I realized that all people can create very beautiful and perfect artworks even if they have a disability" (ST15).

"I was expecting to see the inner world of people with disabilities. I realized that people with disabilities have some problem but they have other excessively high abilities" (ST14).

"I was expecting to see mainly paintings, not sculptures. I am thinking that people with disabilities often are considered helpless. However, they can make better artworks than those of people without disabilities" (ST22).

Regarding STs "ideas about appropriate behavior towards disabled people", they expressed their thoughts about avoiding derogatory behaviors or discrimination, showing respect and providing them opportunities:

"We should not underestimate people with disabilities" (ST14). "Definitely the exhibition opened my eyes more and I saw that all artists are equal. We should not feel pity for them and we should not always identify their work with their disability or their problems" (ST17). "The exhibition was a different experience and a message for all to respect diversity" (ST32). "I am thinking how important it is for people with disabilities to have opportunities to do things and express themselves" (ST1).

Furthermore, STs expressed their views, feelings and thoughts about the "design and context of the exhibition" regarding the museum labels and the lack of information about the specific impairment of each artist and the "messages" of the exhibition. They also mentioned the characteristics of the educational tour in order to "discover" meanings:

"Unless I knew that it was an exhibition of artists with disabilities, I would not be able to see any differences $[\ldots]$ museum labels had no information about the disability of the artist" (ST10).

"I was expecting to see the artists to reveal their skills or their stories. The exhibition had many more meanings than we expected" (ST28).

"I think that the way we "looked" at the artworks was different. The educational tour was not just information, but instead we discussed first and we expressed what we were thinking" (ST9).

"In some cases, references to disability were indirect, so we had to discover the meaning of an artwork during our visit" (ST16).

The results of the next five closed-ended questions reflect the STs' views about the educational and social value of relevant practices within museums $\left(4^{\text {th }}\right.$ research question). These five questions are Q6 to Q9: "To what extent do you consider that art exhibitions of disabled artists in museums have a pedagogical value for: disabled children, non-disabled children, general education teachers and special education teachers [respectively]" and Q10: "To what extent do you consider that art exhibitions of disabled artists in museums have a social value for the broader community". A 5-point Likert-type scale, from 1 ("Not at all") to 5 ("Very Much"), was used and 
revealed a high agreement of the STs with regards to the educational and social value of museum art exhibitions of disabled artists for different target groups. In total the participants expressed clearly positive views for all the above questions/items $(\mathrm{M}=4.73, \mathrm{SD}=0.351)$. Furthermore, a Kruskal-Wallis test was conducted regarding the STs' views from different semesters, but there was no statistically significant difference.

An open-ended question (Q11 "Could you please comment or explain your answers in the above questions, e.g., why, how, etc.?") was also included for the STs' comments with regards to their responses in the aforementioned closed-ended questions. Based on the answers of STs, the following Table (Table 3) presents the reasons for which art exhibitions of disabled artists in museums have value - pedagogical and social - for the previously cited target groups and the broader society. Furthermore, apart from the target groups mentioned in the closed-ended questions, some STs also referred to the parents of disabled children.

Table 3. Student teachers' views about the pedagogical and social value of art exhibitions of disabled artists in museums

\begin{tabular}{ll}
\hline Target groups/audiences & Value of art exhibitions of disabled artists in museums \\
\hline Disabled children & Self-confidence \\
& Motivation to engage in arts \\
& Sense of equality \\
& Acceptance \\
& Social inclusion \\
& Sense of community \\
& Creativity \\
& Understanding of disability \\
Non-disabled children & Acceptance of disabled children/people \\
& Positive perceptions towards disability \\
& Motivation to engage in arts \\
& Creativity \\
& Understanding of disability \\
& Knowledge \\
& Avoiding underestimation of disabled children in inclusive \\
General education teachers & educational settings \\
& Promoting positive attitudes \\
& Ideas for awareness activities in schools \\
& Learning opportunities to all children \\
& Arts as a pedagogical tool \\
& Activities with arts \\
& Activities in museums \\
Special education teachers & Empowerment \\
Parents of disabled children & Contact with disabled people and artists \\
Broader society & Raising disability awareness \\
& Reducing stereotypes \\
& Developing respect to diversity \\
\hline & \\
&
\end{tabular}

As seen in Table 3 and regarding the benefits and the value of art exhibitions of disabled artists in museums, STs reported common benefits, as for example the creativity and the motivation to engage in arts for all children. For disabled children they reported that the contact - even indirect - with disabled adults and artists can enhance their self-confidence, the sense of equality, acceptance and social inclusion. According to the STs, it is also very important for Deaf children to feel very "proud" for their language and Deaf people when they see Sign Language in paintings. In case of non-disabled children, STs mentioned how important it is to promote positive attitudes to children in early age. Arts and specific artworks of disabled people can "show" that all people have capabilities and are equal which, in turn, can promote acceptance, a better understanding and positive perceptions towards disability. The following extracts are representative of the aforementioned ideas:

"Arts always inspire children with and without disabilities to develop their creativity and their motivation with regards to arts" (ST24). "The artworks have a very important pedagogical value for all children" (ST10). "...for children with disabilities are very important [these exhibitions], they feel acceptance and included in the society" (ST17). "These exhibitions can contribute to the self-confidence of children with 
disabilities and also motivate them to engage in the arts" (ST13). “.. a Deaf child would be very proud to see the Sign Language in a painting" (ST10).

STs also expressed various benefits for general education teachers in terms of understanding disability, knowledge about disabled children and promotion of positive attitudes towards disability and children with disabilities in inclusive educational settings. They also referred to the importance of providing learning opportunities to all children and also to be inspired by arts and disabled artists in order to organize awareness activities in schools. In the case of special education teachers, the participants referred generally to arts as a pedagogical tool and a way of expression of children with disabilities and also to museum activities:

"I think these exhibitions are very important because all of us [teachers]... we can have a contact, even indirect, with disabled artists and this can contribute to a better understanding" (ST2).

"There are a lot of stereotypes for people with disabilities which begin from an early age. These exhibitions help children to acquire more positive perceptions of the world around them and for people with disabilities. For general education teachers these exhibitions help to confront diversity in a unique way and promote positive attitudes to [non disabled] children towards children with disabilities" (ST4).

"[the exhibition] can contribute to other general knowledge and other things that I have studied about special education" (ST15).

"Disability awareness is extremely important especially for teachers both of general and special education. Because we will work with children with disabilities and in general classrooms. It is a duty to know and better learn children with disabilities" (ST22).

"For us [general teachers] these opportunities are very important because it is possible to work with children with various difficulties or disabilities in the general school. I can understand how important it is for children with disabilities to express themselves through arts" (ST27).

"They [the disabled artists' exhibitions] can make us understand and teach to the children respect and acceptance of diversity" (ST28).

"We can learn a lot from these exhibitions and we can also have ideas about how we can use arts with children as for example activities for disability awareness in school" (ST24).

"As teachers we realize how many things children with disabilities can do and we should provide them with opportunities to express themselves" (ST3).

"Special education teachers definitely can be based on these artworks and arts to create "steps" for their students" (ST4).

"Special teachers can bring children in contact with this way of thinking through this exhibition and in museums" (ST10).

STs also referred to parents of children with disabilities and the way these exhibitions can empower them and help them to see what adults and in specific disabled artists are capable of doing. Furthermore, according to the STs answers, parents can also have contact with disabled artists. Regarding the social value of relevant activities and exhibitions, STs referred to values as for example respect to diversity, eliminating stereotypes and better understanding of disability:

"I also think that it can be very important also for the parents of children with disabilities to see what their children can do, to know artists with disabilities" (ST24). "These exhibitions have a lot of value...to respect these people" (ST18). "For people without disabilities are definitely very important because they offer an opportunity to all to realize that we should not underestimate people we call "special" (ST14). "Every art exhibition is an inspiration for different people. However, exhibitions like this one [with disabled artists] offer food for thought to everyone to see the world in a different way" (ST29). "These exhibitions can have many meanings but mainly the message is that we can all participate in our own way. Arts have a tremendous power" (ST30).

However, it is worth mentioning that STs also commented that disabled artists' exhibitions are rare and events like this should be more frequent with appropriate programs and activities for children and adults (educational programs, guided tours, etc) according to their needs.

\section{Discussion}

The present study entails some limitations that cannot allow the generalization of its results with regards to Primary Education student teachers' knowledge about disabled artists. This is because the number of participants 
is small and from one university department. Furthermore, the study refers to a specific case of an art exhibition by disabled artists, with specific content in terms of artworks, themes, concept and design. It is also clear that the present study does not examine issues of changing attitudes since the latter are affected by a number of other variables which are beyond the research framework and its questions. Nevertheless, the present study can open up or contribute to the current discussion about the role of museums, arts, disabled artists' work and enrichment of teachers' education and training in arts and disability arts (Dodd et al., 2010; Symeonidou, 2020; Ware, 2008).

The study is based on the social model of disability that provides a framework about the social construction, images and representations of disability (Oliver, 1990, 2013). It also recognizes the role of museums as authoritative cultural centers which can contribute to promoting activities related to disability, arts and disabled artists' work. Museums can also encourage people - including teachers - to reflect, (re)consider and (re)shape their perceptions about disabled people and to better understand disability (Dodd et al., 2010; Sandell et al., 2010). The constructivist learning theory and the recognition of contextual learning are also important in the present study, since we learn and construct our meanings actively, individually - based on prior knowledge, perceptions, experiences, prejudices, etc. - and socially (Hein, 1991). Thus, the discussion of the present study enables issues with regards to: the diffusion and establishment of the social model of disability (Oliver, 1990); the persisting stereotypes towards disability (Dodd et al. 2010; Oliver, 1990); the degree of active presence and the role of disability movements, disabled artists and disability arts movement (British Council - Disability Arts International, 2019; Sulewski, Boeltzig, \& Hasnain, 2012); the development of inclusive education (Ainscow, 2020 ) and teachers' training practices in disability issues related to arts and disabled artists' works (Symeonidou, 2020; Ware 2008); museums' resources and activities related to disability themes and social inclusion (Dodd \& Sandell, 2001; Sandell, 2002) and curatorial practices within museums towards an inclusive society and an "inclusive art world" (Hylton, 2007:115). The above issues are reflected on the results of the research questions.

The results regarding STs' prior knowledge and experience about disabled artists revealed narrow background knowledge. None of them referred to learning experiences related to disabled artists' work during the school years or university courses and none of them had ever seen a similar exhibition. STs' knowledge about disabled artists included mainly the mouth and foot painting artists. Their knowledge had been acquired incidentally by activities of associations of disabled people, as for example distribution of calendars and cards for Christmas wishes with artworks of disabled persons or by other resources of information, like TV programs. Although definitely foot and mouth painting artists are known abroad and in Greece, as well as their associations that promote their work and support them [see, e.g., the MFPA - Mouth and Foot Painting Artists website in United Kingdom (Note 8) and the ZOSP - Association of Mouth and Foot Painting Artists in Greece (Note 4)], artists with physical and mobility impairments also use many other media of artistic expression. Moreover, the history of art as well as the contemporary visual arts scene has many disabled and Deaf artists who use various media of arts. However, STs did not refer to disabled artists other than foot and mouth painting artists.

The above are reflected on STs' expectations about the exhibition, the disabled artists and the content/subject of the artworks. More precisely, within the comments of the STs one comes across different aspects and perceptions related to disabled artists' work. For example, STs were expecting to see foot and mouth paintings and the type of impairment of disabled artists. Disabled artists often reflect issues of disability in their artworks in terms of disability identity, acceptance and pride, experiences and effects of impairment in their lives (Sulewski et al., 2012). However, STs' comments had no mentions about disability identity in this sense. Furthermore, some STs were expecting to see clearly the impairment of each disabled artist or themes related to "pain", "difficulties" or "how they imagine their life without disability". These comments seem to be closer to the individual model of disability rather than the social model (Oliver, 1990) and disability arts movement (Sulewski et al., 2012) which is opposed to the image of disabled artists as helpless and dependent persons (Darling, 2003 as cited in Sulewski et al., 2012). Although the social model of disability is dominant in the current discourse and policy practices, the above show that some perceptions about disabled people still reflect aspects of the individual model of disability. This is in line with the findings of other relevant research (Valentine \& MacDonald, 2004 as cited in Dodd et al., 2010). The lack of knowledge for disabled artists is also reflected on STs' expectations with regards to techniques and media. As mentioned above, STs expected to see mouth and foot paintings; others expected clay artworks or artworks with "bizarre" images made with "different" materials and ways. However, in this case "different" was not meant in terms of variety of media. For example, there were STs that did not even expect to see sculptures.

These findings lead the discussion to basic and critical parameters regarding the lack of relevant experiences in school, art curriculum and disabled artists' work, the degree of presence of disabled artists in the art and social scene, the diffusion of relevant practices and the role of cultural institutions, as for example museums. They also 
indicate the need for a more systematic education with regards to disabled artists in formal education, as well as in nonformal cultural learning environments, as for example museums. The aforementioned, in conjunction with STs' highly positive views about the value of the arts and museums in disability awareness, are in line with relevant researches and studies that highlight the role of the arts and disabled artists' work in the enrichment of curriculum or/and disability awareness activities towards the development of inclusive education (see, e.g., Seidler, 2011; Symeonidou, 2018; Symeonidou \& Loizou, 2018). They can also be associated with the contemporary discussion of museums' role in issues of diversity including disability (Sandell et al., 2010). In Greece many steps have been made towards inclusive education (Strogilos, 2012; Strogilos et al., 2017) and many museums across the country develop educational programs for children and adults with disabilities (Katselaki \& Sakali, 2020). However, the initiatives for art exhibitions of disabled artists within museums are not very common, especially in museums which are far from large urban centers. As for evaluation, despite the examples of other museums exhibitions' evaluation (Bounia, 2015) and educational programs for disabled people - adults and children - (see, e.g., Emmanouil \& Avgoulas, 2011; Kanari \& Souliotou, 2020), in the case of disabled artists' exhibitions there is a lack of published evaluation studies about visitors' responses.

Regarding the reflections of STs after visiting the exhibition "Travelling Art" and participating in the educational tour that was designed in order to promote active engagement and not simply to provide or convey information, STs expressed a range of ideas compared to their prior expectations. At this point, it is worth mentioning that researches in the field of museum studies emphasize the fact that museums are not spaces of "moral coercion" (Sandell \& Dodd, 2010: 20) or spaces where knowledge is transmitted to passive receivers of information. Museums are, instead, spaces that promote, through a range of methods and means, the active engagement of visitors in order to challenge their perceptions and construct their own meanings (Black, 2012; Sandell \& Dodd, 2010). The constructivist learning theory, besides the role of individual as learner, also stresses the importance on the nature of learning as a social activity (Hein, 1991).

The educational tour of STs in the museum for the specific exhibition used methods and activities (e.g., discursive methods, experiential activities) in order to encourage STs to reflect on their own prior expectations and perceptions, to share ideas and to (re)discover and construct meanings. STs' ideas and thoughts afterwards were expanded since they realized that disabled artists can clearly express issues of disability in their artworks, use symbolic ways to express messages about disability, express issues related to their culture (e.g., in the case of Deaf culture and Sign Language) or other general themes related to life, nature, etc. The aforementioned are described in the literature with regards to arts and disability identity, artist identity or intersecting identities (Sulewski et al., 2012). STs commented also on the lack of information about the type of artists' impairment and the absence of their biography in the exhibits' labels. The issue of curatorial practices within museums in relation to disability, arts and disabled artists' work is an important topic of discussion and there are different views and approaches (Sandell \& Dodd, 2010). In the case of disabled artists' exhibitions, as Cashia (2013) states, there are exhibitions with clearly activist orientation and intent or exhibitions with intersectional approaches. The majority of STs also commented on the capabilities of disabled people and disabled artists in terms of equality and respect and the importance of avoiding prejudices, stereotypes and discrimination. However, in a few cases there were also comments about "better artworks than those of people without disabilities" or disabled artists who have "transcended" their disability. The latter leads the discussion to stereotypes that this time imply the idea of the disabled as "heroic" persons (Oliver, 1990; Sandell et al., 2005). Although the activities during the educational tour were designed in order to encourage STs to challenge their perceptions towards a more realistic view of disabled artists and people, it seems that specific types of perceptions are very strong and since they are not negative, they are not conceived as prejudices or stereotypes (Dodd et al., 2010) by the STs. Of course, it cannot be argued that a single visit to a museum in a disabled artists' exhibition can lead or assure the change of attitudes. Furthermore, as mentioned above, in the frame of the constructivist learning theory learning is contextual, active and social and of course it needs time (Hein, 1991). The aforementioned are also in line with contemporary discussions about disability and inclusion with regards to the need for systematic changes and synergies among different levels of the society, institutions, formal, nonformal education and learning environments (Spandagou, 2011).

Last, STs' views about the pedagogical and social value of the museums in relation to disability and disabled artists were very positive stressing also different ways in which relevant practices in museums can benefit disabled and non-disabled children, teachers, parents of disabled children and the broader society. Regarding their own role as future teachers working in inclusive educational settings, STs referred to issues of expanding their knowledge with regards to arts and disabled artists' work, better understanding of disability and ways to use this knowledge with their students for awareness activities in schools. They also mentioned their "duty to better 
know and learn children with disabilities", the ways to provide learning opportunities to all children as well as to promote positive attitudes and appropriate behaviors towards children with disabilities in inclusive educational settings. The aforementioned are aligned with other relevant researches and studies that investigate how -among others- arts and disabled artists' work can contribute to the promotion of inclusive education, the enhancement and the enrichment of student teachers and in-service teachers' training or/and professional development as well as the need for further research in the specific field (see, e.g., Allan, 2014; Chrysostomou \& Symeonidou, 2017; Symeonidou, 2018, 2020; Ware, 2008). Thus, the results show that museum learning environments can contribute to the aforementioned discussion about the arts and disabled artists' work in teachers' training and education. They also confirm museums' role towards disability awareness and inclusive society (Dodd \& Sandell, 2001; Dodd et al., 2010).

\section{Conclusions and Suggestions}

Over the past decades the discourse of human rights and the social model of disability has influenced policies, legislation, practices, education, museums, etc. (McGhie, 2020; Oliver, 2013; Sandell \& Dodd, 2010; UNESCO, 1994). Nevertheless, there are still many different social barriers including stereotypes and prejudices (Dodd et al., 2010). Cultural representations and images of disabled people and perceptions towards disability are a major issue of discussions, research and practices in various contexts and fields including disability studies, cultural institutions, as for example museums, arts, different levels of education, etc. (see, e.g., Oliver, 1990; Campbell, et al., 2003; Sandell et al., 2010). Art bridges the individual with the social by extending individualities to others' experiences and to the surrounding world. Art also gives the possibility for the individual to share ideas and to link with others and finally turns out to be a catalyst for humans to deeply recognize and to change the world (Fischer, 1959) and contribute to the sustainable development and to more cohesive societies (Hawkes, 2001). Postmodernism and contemporary art largely investigate issues of identities and within this framework art made by different social groups is widely recognized as an integral part of the art world (Reed, 1994). Arts have an important role for disabled people and disability identity (Sulewski et al., 2012) and social inclusion with potential multiple benefits in education of children and student teachers towards inclusion, inclusive education and disability awareness (see, e.g., Symeonidou, 2020; Symeonidou \& Loizou, 2018).

In this framework Museum Education and museums as nonformal, rich and stimulating cultural learning environments (Black, 2012), can actively contribute to the aforementioned discussion in many ways including activities that support and complement different levels of formal education as for example STs' education in disability, arts, disabled artists' work and disability awareness. Indeed, museums of the $21^{\text {st }}$ century through a range of activities that promote community dialogue, understanding and respect to diversity develop a more and more important and expanded role towards inclusive and cohesive societies (Black, 2012; Dodd \& Sandell, 2001; Hooper-Greenhill et al., 2000; Sandell et al., 2010). From the above exhibition of disabled artists, museum visit and research it becomes obvious that it is possible for art and museum activities to challenge preconceptions and stereotypes about social groups, as for example disabled people. In the case of the present study, "Travelling Art" exhibition turns out to be a link of the disabled artists with the exhibition visitors and, more specifically, with the STs. Through this link the disabled artists shared their ideas, views, (personal) situation and experience, which were expressed in their artworks. Furthermore, STs had the opportunity to challenge their perceptions of disability. The constructivist learning theory (Hein, 1991) provides the theoretical basis about the influence of prior perceptions, knowledge, experiences, existing cultural representations and images of disability as well as the social dimension of learning.

Thus, initiatives towards inclusion and a better understanding of disability are not "separated" fields of practices, but instead integral parts of the society, education, culture and learning and social experiences in different environments and contexts throughout lifetime. The social demand for the development of an inclusive society that respects diversity and human dignity requires changes, collaborations and synergies at different levels of the society (Spandagou, 2011) within a systematic and systemic approach. Alongside with the need for a more systematic use of arts and disability arts in STs' training and education in disability issues and inclusive education, museums can contribute to this dynamic and multidisciplinary field of relevant research and practices with many potential implications in and across different scientific fields. Museum exhibitions of disabled artists' works, workshops, programs, etc., related to disability and arts, enrich and reveal museums' role in terms of equity, education, culture and inclusion. Since many of these practices often are part of museum activities with a temporary character (e.g. temporary exhibitions) and of course not all museums have the same resources, it is important to be aware of the benefits of such collaborations, partnerships, synergies and networks among museums, universities and disabled artists or/and disabled artists' associations. The international experience has many examples of collaborations between universities and museums for university students' and student teachers' 
training and education (see, e.g. Clark et al., 2016; Nichols, 2014). By taking into account the specific characteristics and resources of each institution and the local or broader society and community context, museums and universities should seek to promote collaborations with the active involvement of disabled artists or associations of disabled people and artists within interdisciplinary and participatory practices (Simon, 2010). Further research, evaluation of relevant activities and dissemination of results and good practices should definitely enrich the current dialogue and practices regarding disability awareness, the elimination of prejudices and stereotypes as well as teachers' training in disability and inclusive education. Based on the ICOM moto "Museums have no borders, they have a network" (Note 9), the ultimate aim should be to create networks for the benefit of all people, disabled and non-disabled and for the improvement of quality of life and inclusive society.

\section{References}

Ainscow, M. (2020). Promoting inclusion and equity in education: Lessons from international experiences. Nordic Journal of Studies in Educational Policy, 6(1), 7-16. https://doi.org/10.1080/20020317.2020.1729587

Ainscow, M., Dyson, A., \& Weiner, S. (2013). From exclusion to inclusion: ways of responding in schools to students with special needs. Centre for Equity in Education, University of Manchester. Retrieved from https://files.eric.ed.gov/fulltext/ED546818.pdf

Allan, J. (2014). Inclusive education and the arts. Cambridge Journal of Education, 44(4), 511-523. https://doi.org/10.1080/0305764X.2014.921282

Allday, K. (2009). From changeling to citizen: Learning disability and its representation in museums. Museum and Society, 7(1), 32-49.

Ambrose, T., \& Paine, C. (2018). Museum Basics. London: Routledge. https://doi.org/10.4324/9781315232898

ARTOGETHER (2019). Travelling Art. 25 artists with disabilities, 25 writers' manuscripts, 5 exhibition spaces. [Exhibition catalogue] (in Greek).

Avramidis, E., \& Kalyva, E. (2007). The influence of teaching experience and professional development on Greek teachers' attitudes towards inclusion. European Journal of Special Education, 22(4), 367-389. https://doi.org/10.1080/08856250701649989

Avramidis, E., \& Norwich, B. (2002). Teachers' attitudes towards integration/inclusion: a review of the literature, European Journal of Special Needs Education, 17(2), 129-147. https://doi.org/10.1080/08856250210129056

Bennett, T. (1995). The birth of the museum. History, theory, politics. London: Routledge.

Black, G. (2012). Transforming museum in the twenty first century. London: Routledge. https://doi.org/10.4324/9780203150061

Black, G. (2005). The engaging museum. Developing museums for visitor involvement. London-N.Y.: Routledge.

Barnes, C., Mercer, G., \& Shakespeare, T. (1999). Exploring disability. A sociological introduction. Cambridge: Policy Press.

Bounia, A. (2015). Visitors' research and evaluation. The audience's "voice". In N. Nikonanou (Ed.), Museum learning and experience in 21st century (pp.147-169). [ebook]. Athens: Hellenic Academic Libraries Link (in Greek). Retrieved from

https://repository.kallipos.gr/pdfviewer/web/viewer.html?file=/bitstream/11419/718/1/02_chapter_7.pdf

British Council - Disability Arts International (2019). Greece Country profile. Retrieved January 8, 2021 from https://www.disabilityartsinternational.org/resources/greece-country-profile/

Cachia, A. (2014). From outsider to participant: Developmentally disabled dialogue in socially engaged art. Museums and Social Issues, 9(2), 109-123. https://doi.org/10.1179/1559689314Z.00000000022

Cachia, A. (2013). Disabling the museum: Curator as infrastructural activist. Journal of Visual Art practice, 12(3), 257-289. https://doi.org/10.1080/14702029.2013.10820082

Campbell, J., Gilmore, L., \& Cuskelly, M. (2003). Changing student teachers' attitudes towards disability and inclusion. Journal of Intellectual \& Developmental Disability, 28(4), 369-379. https://doi.org/10.1080/13668250310001616407

Chrysostomou, M., \& Symeonidou, S. (2017). Education for disability equality through disabled people's life stories and narratives: Working and learning together in a school based professional development 
programme. European Journal of Special Needs Education, 32(4), 572-585.

https://doi.org/10.1080/08856257.2017.1297574

Cohen, L., \& Manion, L. (1994). Research methods in education. London \& New York: Routledge.

Clark, M., Ensminger, D., Incandela, C., \& Moisan, H. (2016). Reflections on museums as effective field sites for teacher candidates. Journal of Museum Education, 41(4), 329-340. https://doi.org/10.1080/10598650.2016.1219127

Coxall, H. (2006). Open minds: Inclusive practices. In H. H. Genoways (Ed.), Museum philosophy for the twenty-first century (pp. 139-149). United States: Altamira Press.

Creswell, W. J. (2015). Educational research. Planning, conducting and evaluating quantitative and qualitative research. Pearson Education Inc.

Delin, A. (2002). Buried in the footnotes: The absence of disabled people in the collective imagery of our past. In R. Sandell (Ed.), Museums, society, inequality (pp. 84-97). London: Routledge.

Dey, I. (1993). Qualitative data analysis. A user-friendly guide for social scientists. London: Routledge.

Dodd, J., Jones, C., Jolly, D., \& Sandell, R. (2010). Disability reframed. Challenging visitor perception in the museum. In R. Sandell, J. Dodd \& R. Garland-Thomson (Eds.), Representing disability, activism and agency in the museum (pp. 92-111). London: Routledge.

Dodd, J., Sandell, R., Jolly, D., \& Jones, C. (Eds.). (2008). Rethinking disability representation in museums and galleries. Leicester: Research Centre for Museums and Galleries, Department of Museum Studies, University of Leicester. Retrieved from http://www2.le.ac.uk/departments/museumstudies/rcmg/projects/re thinking-disability-representation-1/rdrsmallest.pdf

Dodd, J., \& Sandell, R. (Eds.). (2001). Including museums. Perspectives on museums, galleries and social inclusion. Leicester: Research Centre for Museums and Galleries, Department of Museum Studies, University of Leicester. Retrieved from https://le.ac.uk/rcmg/research-archive/including-museums

Eisenhauer, J. (2007). Just looking and staring back: Challenging ableism through disability performance. Art, Studies in Art Education, 49(1), 7-22. https://doi.org/10.1080/00393541.2007.11518721

Emmanouil, M., \& Avgoulas, V. (2011). The response of special audience to the educational program for people with visual impairments of the exhibition "The Pre-Columbian Art in Benaki Museum". Evaluation of demand and supply in cultural goods. In Proceedings of the 2nd Greek Conference in Special Education. Athens: Grigoris (in Greek). pp. 397-406.

Eshach, H. (2007). Bridging in-school and out-of-school learning: formal, non-formal, and informal education. Journal of Science Education and Technology, 16(2), 171-190. https://doi.org/10.1007/s10956-006-9027-1

Falk, J. H., Dierking, L. D., \& Adams, M. (2006). Living in a learning society: Museums and free-choice learning. In S. Macdonald (Ed.), A companion to museums studies (pp. 323-339). Oxford: Blackwell Publishing. https://doi.org/10.1002/9780470996836.ch19

Falk, J. H., \& Dierking, L. D. (2013). The museum experience revisited. London- NY: Routledge.

Falk, J. H., \& Dierking, L. D. (2000). Learning from museums: Visitor experiences and the making of meaning. Walnut Creek, CA: AltaMira.

Fischer, E. (1959). The Necessity of Art: A Marxist Approach. (Translation: Anna Bostock). Middlesex, Maryland, Victoria: Penguin Books.

Gibbs, K., Sani, M., \& Thompson, J. (Eds.). (2007). Lifelong learning in museums. A European handbook. Ferrara: EDISAI srl. Retrieved from http://online.ibc.regione.emilia-romagna.it///libri/pdf/LifelongLearninginMuseums.pdf

Grajcevci, A., \& Shala, A. (2016). Formal and non-formal education in the New Era. Action Researcher in Education, 7, 119-130.

Hansen, A. (2014). The heritage learning framework and the heritage learning outcomes. In D. Christidou (Ed.), Implementing heritage learning outcomes (pp. 7-24). Östersund: JamtliFörlag, Fornvårdaren 37.

Harvey, M. W., Yssel, N., Bauserman, A. D., \& Merbler, J. B. (2010). Preservice teacher preparation for inclusion: An exploration of Higher Education teacher-training institutions. Remedial and Special Education, 3(1), 24-33. https://doi.org/10.1177/0741932508324397 
Hawkes, J. (2001). The fourth pillar of sustainability. Culture's essential role in public planning. Melbourne, Australia: Common Ground Publishing Pty Ltd, Cultural Development Network.

Hein, G. (2006). Museum education. In S. Macdonald (Ed.), A companion to museums studies (pp. 340-352). Oxford: Blackwell Publishing. https://doi.org/10.1111/b.9781405108393.2006.00026.x

Hein, G. (1999). The constructivist museum. In E. Hooper-Greenhill (Ed.), The educational role of the museum (pp.73-79). London: Routledge.

Hein, G. (1998). Learning in the museum. London: Routledge.

Hein, G. (1991). Constructivist learning theory. International Committee of Museum Educators Conference. Jerusalem Israel. Retrieved from https://www.exploratorium.edu/education/ifi/constructivist-learning

Hooper-Greenhill, E. (2007). Museums and education. Purpose, pedagogy, performance. London: Routledge. https://doi.org/10.4324/9780203937525

Hooper-Greenhill, E. (2006). The power of museum pedagogy. In: H. H. Genoways (Ed.), Museum philosophy for the twenty-first century (pp. 235-245). United States: Altamira Press.

Hooper-Greenhill, E., Sandell, R, Moussouri, T., \& O'Riain, H. (2000). Museums and social inclusion-The GLLAM report. Leicester: Research Centre for Museums and Galleries, Department of Museum Studies, University of Leicester. Retrieved from https://le.ac.uk/rcmg/research-archive/museums-and-social-inclusion

Hsiao, Y. J. (2020). The impact of interaction with adults with disabilities on preservice general education students' attitudes towards disability and inclusion. International Journal of Disability, Development and Education. https://doi.org/10.1080/1034912X.2020.1774047

Hylton, R. (2007). Thoughts of curating. In J. Rugg \& M. Sedwick (Eds.), Issues in curating contemporary art and performance (pp. 113-127). USA: Intellect Ltd.

ICOM. (2017). International Council of Museums (ICOM) - Statutes. As amended and adopted by the Extraordinary General Assembly on $9^{\text {th }}$ June 2017 (Paris, France). Retrieved from https://icom.museum/wp-content/uploads/2018/07/2017_ICOM_Statutes_EN.pdf

Jacobson, R., \& McMurchy, G. (2010). Focus on disability and Deaf arts in Canada. A report from the field. Canada: Canada Council of the Arts. Retrieved from https://canadacouncil.ca/research/research-library/2011/09/focus-on-disability-and-deaf-arts-in-canada

Jobling, A., \& Moni, K. B. (2004). "I never imagined I'd have to teach these children": Providing authentic learning experiences for secondary pre-service teachers in teaching students with special needs. Asia-Pacific Journal of Teacher Education, 32(1), 5-22. https://doi.org/10.1080/1359866042000206026

Kalaitzaki, N. (2018, August, 29). In your eyes. Approaching blindness. Curator: Nikolena Kalaitzaki, 13-25.9.18 [Video]. YouTube. Retrieved from https://www.youtube.com/watch?v=uL33iAhXAHA

Kanari, Ch., \& Souliotou, A. Z. (2020). Education of children with disabilities in nonformal learning environments: A cross-disciplinary approach of STEAM Education in a technological museum in Greece. European Journal of Alternative Education Studies, 5(2), 1-34. https://doi.org/10.46827/ejae.v5i2.3188

Katselaki, A., \& Sakali, O. (Eds.). (2020). Culture for all. Museums and monuments without exclusions. Proceedings of an Interdisciplinary Conference, Athens 29-30 November 2018. Athens: Ministry of Culture and Sports (in Greek).

Koltsida, M., \& Lenakakis, A. (2017). Contemporary performance by and those with disabilities: The case of Greece. Research in Drama Education: The Journal of Applied Theatre and Performance, 22(3), 339-344. https://doi.org/10.1080/13569783.2017.1326809

Koutsoubelitsi, N., Chavela, K., \& Manolopoulou, G. (2020). The Archaeological Museum of Patras as a mosaic for the formation of a social network based on cultural heritage as a connecting material. The "Human chain" at the Museum of Patras. In A. Katselaki, \& O. Sakali (Eds.), Proceedings Culture for all. Museums and monuments without exclusions (pp. 31-38). Athens: Hellenic Republic- Ministry of Cultures and Sports.

Lazarou, D. (2020). Official video. Art bulletin in Sign Language@ Tsichritzis Foundation for the Visual Arts. Exhibition [Video]. YouTube. Retrieved from https://www.youtube.com/watch?v=gR1tG8rmDIM

Li, K. M., \& Cheung, R. Y. M. (2019). Pre-service teachers' self-efficacy in implementing inclusive education in Hong Kong: The roles of attitudes, sentiments, and concerns. International Journal of Disability, 
Development and Education. https://doi.org/10.1080/1034912X.2019.1678743

Loreman, T., Sharma, U., \& Forlin, C. (2013). Do pre-service teachers feel ready to teach in inclusive classrooms? A Four country study of teaching self-efficacy. Australian Journal of Teacher Education, 38(1). http://dx.doi.org/10.14221/ajte.2013v38n1.10

Martins, P. R., Semedo, A. L, \& Camacho, C. F. (Eds.). (2018). Representing disability in museums. Imaginary and identities. Porto: CITCEM - Centro de Investigação Transdisciplinar Cultura, Espaço e Memória. https://doi.org/10.21747/9789898970114/repr

McCulloh, D. (2013). Blind photographers: Vision, accessibility and empowerment in the museum. Disability Studies Quarterly, 33(3). https://doi.org/10.18061/dsq.v33i3.3739

McGhie, H. (2020). Museums and human rights: Human rights as a basis for public service. UK: Curating Tomorrow. Retrieved from www.curatingtomorrow.co.uk

Mowlah, A., Niblett, V., Blackburn, J., \& Harris, M. (2014). The value of arts and culture to people and society an evidence review. London: Arts Council England. Retrieved from https://www.artscouncil.org.uk/sites/default/files/download-file/Value_arts_culture_evidence_review.pdf

Newman, A., McLean, F., \& Urquhart, G. (2005). Museums and the active citizen: Tackling the problems of social exclusion. Citizenship Studies, 9(1), 41-57. https://doi.org/10.1080/1362102042000325351

Nichols, K. S. (2014). Museum and universities \& pre-service teachers. Journal of Museum Education, 39(1), 3-9. https://doi.org/10.1080/10598650.2014.11510790

Nikonanou, N., Bounia, A., Bennett, A., \& Kirwan, A. (2020). Creating learning experiences in museums. Discussing, inquiring, participating. UCL-Qatar- National Museum of Qatar.

Oliver, M. (2013). The social model of disability: Thirty years on. Disability and Society, 28(7), 1024-1026. https://doi.org/10.1080/09687599.2013.818773

Oliver, M. (1990). The politics of disablement. London: Macmillan. https://doi.org/10.1007/978-1-349-20895-1

Reed, C. (1994). Postmodernism and the Art of Identity. In N. Stangos (Ed.), Concepts of modern art: from fauvism to postmodernism (3rd edit). London: Thames and Hudson.

Robson, C. (1997). Real World Research. Oxford: Blackwell.

Sandell, R. (2007). Museums, prejudice and the reframing of difference. London: Routledge. https://doi.org/10.4324/9780203020036

Sandell, R., \& Dodd, J. (2010). Activist practice. In R. Sandell, J. Dodd, \& R. Garland-Thomson (Ed.), Re-presenting disability. Activism and agency in the museum (pp. 3-22). London: Routledge.

Sandell, R., Dodd, J., \& Garland-Thomson, R. (Eds.). (2010). Re-presenting disability. Activism and agency in the museum. London: Routledge.

Sandell, R., Delin, A., Dodd, J., \& Gay, J. (2005). Beggars, freaks and heroes? Museum collections and the hidden history of disability. Museum Management and Curatorship, 20(1), 5-19. https://doi.org/10.1080/09647770500302001

Sandell, R. (2003). Social inclusion, the museum and the dynamics of sectoral change. Museum and Society, 1(1), 45-62.

Sandell, R. (2002). Museums and the combating of social inequality: Roles, responsibilities, resistance. In R. Sandell (Ed.), Museums, society, inequality (pp. 3-23). London: Routledge. https://doi.org/10.4324/9780203167380-8

Seidler, C. (2011). Fighting disability stereotypes with Comics: "I cannot see you, but I know you are staring at me". Art Education, 64(6), 20-24. https://doi.org/10.1080/00043125.2011.11519148

Sharma, U., Forlin, C., \& Loreman, T. (2008). Impact of training on pre-service teachers' attitudes and concerns about inclusive education and sentiments about persons with disabilities. Disability \& Society, 23(7), 773-785. https://doi.org/10.1080/09687590802469271

Simon, N. (2010). The participatory museum. Museum 2.0: Santa Cruz. Retrieved from http://www.participatorymuseum.org/buy/

Sokal, L., Woloshyn, D., \& Funk-Unrau, S. (2013). How important is practicum to pre-service teacher development for inclusive teaching? Effects on efficacy in classroom management. Alberta Journal of 
Educational Research, 59(2), 285-298.

Spandagou, I. (2011). Museums and inclusive education of children with disabilities. In D. Kalesopoulou (Ed.), Child and education in museum. Theoretical origins, pedagogical practices. Hellenic Children's Museum (pp. 113-124). Athens: Patakis (in Greek).

Strogilos, V. (2012). The cultural understanding of inclusion and its development within a centralised system. International Journal of Inclusive Education, 16(12), 1241-1258. https://doi.org/10.1080/13603116.2011.557447

Strogilos, V., Tragoulia, E., Avramidis, E., Voulagka, A., \& Papanikolaou, V. (2017). Undersanding the development of differentiated instruction for students with and without disabilities in co-taught classrooms. Disability \& Society, 32(8), 1216-1238. https://doi.org/10.1080/09687599.2017.1352488

Symeonidou, S. (2020). Teacher education for inclusion and anti-oppressive curriculum development: Innovative approaches informed by disability arts and narratives. International Journal of Inclusive Education. https://doi.org/10.1080/13603116.2020.1711819

Symeonidou, S. (2018). Disability, the arts and the curriculum: Is there a common ground? European Journal of Special Needs Education, 34(1), 50-65. https://doi.org/10.1080/08856257.2018.1435012

Symeonidou, S., \& Loizou, E. (2018). Disability studies as a framework to design disability awareness programs: no need for 'magic' to facilitate children's understanding. Disability \& Society, 33(8), 1234-1258. https://doi.org/10.1080/09687599.2018.1488677

Sulewski, J.S., Boeltzig, H., \& Hasnain, R. (2012). Art and disability: Intersecting identities among young artists with disabilities. Disability Studies Quarterly, 32(1). https://doi.org/10.18061/dsq.v32i1.3034

Tait, K., \& Purduie, N. (2000). Attitudes Toward Disability: Teacher education for inclusive environments in an Australian university. International Journal of Disability, Development and Education, 47(1), 25-38. https://doi.org/10.1080/103491200116110

UNESCO (2017). A guide for ensuring inclusion and equity in education. Paris: United Nations Educational, Scientific and Cultural Organization. Retrieved from file://C:/Users/01CD 1/AppData/Local/Temp/248254eng.pdf

UNESCO (2015). Rethinking education. Towards a global common good? United Nations Educational, Scientific and Cultural Organization. Retrieved from http://unesdoc.unesco.org/images/0023/002325/232555e.pdf

UNESCO (1994). World conference on Special Needs Education. Access and quality. Final report. Paris: UNESCO. Retrieved from https://files.eric.ed.gov/fulltext/ED384189.pdf

Vartiainen, H., \& Enkenberg, J. (2013). Learning from and with museum objects: design perspectives, environment, and emerging learning systems. Education Technology Research and Development, 61(4), 841-862. https://doi.org/10.1007/s11423-013-9311-8

Ware, L. (2008). Worlds remade: Inclusion through engagement with disability art. Inclusion through engagement with disability art. International Journal of Inclusive Education, 12(5-6), 563-583. https://doi.org/10.1080/13603110802377615

Weisen, M. (2008). How accessible are museums today? In H. J. Chatterjee (Ed.), Touch in museums. Policy and practice in object handling (pp. 243-252). Oxford-New York: BERG. https://doi.org/10.4324/9781003135616-24

Zoniou-Sideri, A., \& Vlachou, A. (2006). Greek teachers' belief systems about disability and inclusive education. International Journal of Inclusive Education, 10(4-5), 379-394. https://doi.org/10.1080/13603110500430690

\section{Notes}

Note 1. For more information about the current process at international level for museum definition revision, see https://icom.museum/en/news/icom-define-consultation-2-what-should-be-part-of-the-new-museum-definition/

Note 2. See the festival "Reflection of disability in art" of University of Macedonia. https://rodi.uom.gr/

Note 3. "Goya \& Beethoven at Teloglion". https://www.auth.gr/en/node/14768 
Note 4. Association of Mouth and Foot Painting Artists in Greece (ZOSP). https://zosp.gr

Note 5. For more information about the international exhibition of mouth and foot painters in Athens (2014), see https://vdmfk.com/en/ueber-uns/timeline/2015-2019

Note 6. The exhibition was funded by the Stavros Niarchos Foundation (SNF) with the support of the Career Office of the Athens School of Fine Arts and the Society of Greek Writers.

https://www.piop.gr/en/anakoinoseis/IA-artogether-2019.aspx

Note 7. For more information about the museum network of PIOP, see

https://www.piop.gr/en/diktuo-mouseiwn.aspx, Accessed 3 March, 2021.

Note 8. Mouth and Foot Painting Artists (MFPA) website in United Kingdom. https://www.mfpa.uk/

Note 9. International Council of Museums (ICOM). https://icom.museum/en

\section{Copyrights}

Copyright for this article is retained by the author(s), with first publication rights granted to the journal.

This is an open-access article distributed under the terms and conditions of the Creative Commons Attribution license (http://creativecommons.org/licenses/by/4.0/). 